Boletim Técnico do Instituto Agronômico do Estado de São Paulo

Vol. 15

Campinas, junho de 1956

N.० 12

\title{
EFEITO DE TRÊS TIPOS DE CALCĀRIOS NA REAÇÃO DO SOLO E NO DESENVOLVIMENTO DA SOJA $(*)$
}

J. Romano Gallo, R. A. Catani e H. Gargantini, engenheiros-agrônomos, Seção de Fertilidade do Solo, Instituto Agronómico

\section{RESUMO}

O trabalho teve por objetivo comparar a eficiência de calcários calcítico e dolometicos na correçāo da acidez do solo e sua influência no crescimento da planta e na composição química em cálcio e magnésio, das fôlhas. $O$ ensaio foi instalado com soja, em vasos de Mitscherlich e constou de oito tratamentos com três repetições. Todos os vasos receberam igualmente $\mathrm{N}, \mathrm{P}_{2} \mathrm{O}_{5}$ e $\mathrm{K}_{2} \mathrm{O}$ nas formas de nitrato de amônio, fosfato de amônio e nitrato de potássio. Foram utilizados três calcários diferentes : um altamente cálcico, um dolomítico sediment́ar e um dolomítico típico, em quantidades equivalentes quanto ao valor neutralizante total. $O$ grau de finura dos materiais calcários foi dado por uma mistura, em partes iguais, das frações limitadas pelas peneiras Tyler de 65-150 e 150-270 malhas por polegsada. Ao cabo de 2 meses e meio, as seguintes observações e determinaçōes foram feitas : a) reação do solo $(\mathrm{pH})$ e hidrogênio trocável; b) teor de cálcio e magnésio nas fôlhas; c) desenvolvimento da planta e pêso de material sêco.

Os resultados obtidos permitem concluir que nas condiçñes da experiência em estufa, com o tipo de solo terra roxa misturada, nível químico do solo empregado e com o grau de finura do material utilizado. o comportamento dos calcários calcítico e dolomíticos no solo foram virtualmente iguais no aumento do valor $\mathrm{pH}$ e no decréscimo de $\mathrm{H}^{+}$ trocável. A quantidade de calćário adicionıda, calculada para elevar a saturação em bases do solo a 70\%, elevou o $\mathrm{pH}$ do solo a um valor satisfatório em relação ao esperado.

Quanto ao desenvolvimento dia soja, os calcários acarretaram aumento de produção de hastes e fôlhas. Os calcários dol míticos produziram maior pêso de material sêco.

\section{1 - INTRODUÇÃO}

A incorporação de um câlḉrio ao solo, como corretivo, na maioria das vezes tem dado motivo a certas perguntas quanto a natureza do material destinado à calagem. Assim, é comum procurar-se saber se a calagem é mais eficiente quando feita com calcário do tipo calcítico, que apresenta um teor elevado em cálcio, $40 \%$ ou mais em $\mathrm{CaO}$ e menos de $5 \%$ 
em $\mathrm{MgO}$, ou se o hidrogênio do solo seria igualmente neutralizado mediante a adição de um calcário dolomítico, com teor elevado em magnésio, isto é, 25-30\% em CaO e 15-20\% em MgO. Entre os dolomíticos, os de origem sedimentar teriam mais prontamente efeito sôbre a acidez do solo que os do tipo cristalino?

Segundo investigações conduzidas por Beacher e outros (1), em experiência em vasos, com trêvo, os calcálios calcíticos e dolomíticos de peneira 100 ou malha mais fina, usados em quantidades químicamente iguais, foram igualmente efetivos no aumento do $\mathrm{pH}$ e no decréscimo do hidrogênio trocável do solo. Entre os calcários de grau de finura 10-20 malhas, os dolomíticos reagiram menos intensamente com o hidrogênio do solo, enquanto os calcíticos tiveram maior efeito, em relação a essa característica.

A fim de conseguir algumas informações de caráter preliminar sôbre o assunto, foi instalado um ensaio em vasos, com três calcários diferentes, dos tipos calcítico, dolomítico sedimentar e dolomítico cristalino.

Procurou-se, também, comparar nêste trabalho, os resultados dos testes de laboratório, usados, para fins de calagem, na avaliação da exigência de calcário de um solo, com os dados obtidos no ensaio. $O$ método baseia-se na relaçâo entre $\mathrm{pH}$ e a porcentagem de saturação em bases (2), e as estimativas são feitas a partir do $\mathrm{pH}$ e do $\mathrm{H}^{+}$trocável expresso em equivalentes miligramas por $100 \mathrm{~g}$ de solo. As recomendações de calcário são orientadas para conduzir o solo ao valor $\mathrm{pH} 6,5$, aproximadamente, considerado ótimo para a maioria dos casos. Muitas vêzes, quantidades inadequadas de calcário têm sido reccmendadas. Por êsse método, se as condiçc̃es não forem totalmente satisfeitas, pode-se estar seguro, no entanto, contra os efeitos de uma calagem excessiva.

Além dos objetivos citados, foi estudada a influência dos materiais calcários no crescimento da soja e na composição química das fôlhas, em cálcio e magnésio.

\section{2 - MATERIAL E MÉTODO}

Foram utilizados vasos de Mitscherlich esmaltados, contendo terra roxa misturada, procedente da Estação Experimental Central do Instituto Agronômico, em Campinas, retirada à profundidade de $0-20 \mathrm{~cm}$. Cada vaso recebsu $6 \mathrm{~kg}$ de terra sêca ao ar, passada na peneira de $4 \mathrm{~mm}$ de abertura de malha.

Foram os seguintes os resultados da análise química do solo usado:

$\mathrm{pH}$

Carbono

Nitrogênio (N)

$\mathrm{PO}_{4}^{-3}\left({ }^{1}\right)$

$\mathrm{K}+$ trocsvel

$\mathrm{Ca}+2$ trocivel

$\mathrm{Mg}^{+2}$ trocavel

$\mathrm{H}+$ trocivel
5,30

$2,06 \%$

$0,140 \%$

0,013 e. $\mathrm{mg} / 100 \mathrm{~g}$ de solo sêco

0,18 e. $\mathrm{mg}$

3,63 e. $\mathrm{mg}$

0,87

$5,4.0$

e. $\mathrm{mg}$

e. mg

$\begin{array}{ccc}\text { " } & \text { " } & \\ " & , & " \\ " & , & " \\ , & , & ,\end{array}$

(1) $\mathrm{PO}_{4}^{3}$ extraído com solução de $\mathrm{H}_{2} \mathrm{SO}_{4} 0,05 \mathrm{~N}$. 
Como planta foi empregada a soja (Glycinc max (L.) Merrill), variedade "Abura". As sementes foram inoculadas com inoculante específico "Legume-Aid Inoculant" na proporção de $240 \mathrm{~g}$ de inoculante para 60 $\mathrm{kg}$ de sementes.

O ensaio foi instalado em novembro de 1953 e teve a duração de dois meses e meio, a contar da data da instalação, procedendo-so à colheita quando as plantas mostraram-se em início de florescimento.

Os tratamontos, en número de oito, com três repetiçoes, foram os scguintes : 1 - testemunha geral; 2 - testemunha sem calcário; 3 - 1 dose de calcírio calcítico; 4 -- 2 doses de calcário calítico; $5-1$ dose de caleńrio dolomítico sedimentar; $6-2$ doses de calcário dolomítico sedimentar; 7 - 1 dose de calcário dolomítico cristalino; 8 --- 2 doses de calcírio dolomítico cristalino.

As quantidades de calcários correspondentes a 1 dose foram calculadas para se obter uma saturação cln bases de 70\%. Iissas quantidades são quimisumente equivalentes quanto ao total de neutralizante, e para o cálculo foram considerados o pH e o $\mathrm{H}^{+}$trocível do solo (2).

Os seguintes calcários foram utilizados neste trabalho: calcário de Itaú, material calcítico ou altamente cálcico; calcário de Iimeira, dolomítico sedimentarr; calcário de Taubaté, dolomítico cristalino. Algumas das características dêsses materiais são citadas $\mathrm{cm}$ trabalhos precedentes $(\mathbf{3}, 4)$. O grau de finura dos materiais calcários estudados foi dado por uma mistura, em partes iguais, das fraçóes limitadas polas peneiras Tyler de 65-150 e 150-270 malhas por polegada. Os calcários foram uniformizados quanto ao grau dic finura, para que, na interpretagão dos resultados, caso honvessem variaçós en relag aso ao efeito dos calcários sôbre o $\mathrm{pH}$ e na rodução do $\mathrm{H}^{+}$troéivel do solo, estas não fôsem atribuídas à diversidade granulométrica. A composição química foi a scguinte :

Material

\begin{tabular}{|c|c|c|c|}
\hline Itan $\ldots \ldots \ldots \ldots$ & $\begin{array}{l}\mathrm{CaO} \\
\% \\
47,2\end{array}$ & $\begin{array}{l}\operatorname{MgO}) \\
\% \\
5,1\end{array}$ & $\begin{array}{c}\mathrm{CaCO}_{3} \text { equiv. } \\
\% \\
96,8\end{array}$ \\
\hline 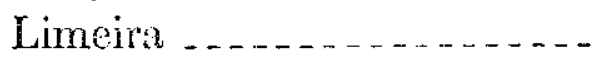 & 27,6 & 19,2 & 96,9 \\
\hline Toubatr. & 31,7 & 19,7 & 105,4 \\
\hline
\end{tabular}

Todos os tratumentos, com excogño do testemurha gersl, receberam por vaso, $2,2 \mathrm{~g}$ de $l_{2} \mathrm{O}_{\mathrm{j}} \mathrm{o} 3,0 \mathrm{~g}$ de $\mathrm{K}_{2} \mathrm{O}$, respectivamente nas formas de $\left(\mathrm{NH}_{4}\right)_{2} \mathrm{HPO}_{4}$; $\mathrm{KNO}_{3}$, on shiño; 2,0 g de $\mathrm{N}$ por vaso, nas formas dos sis citudos e le $\left.\mathrm{NH}_{4} \mathrm{NO}\right)_{3}, \mathrm{~cm}$ solução.

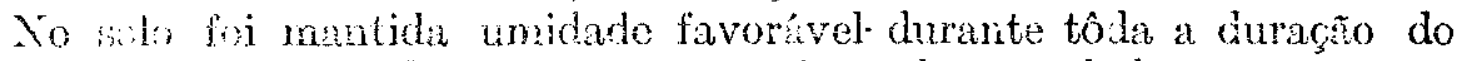
ensaio, procoimono-se, diàriamente, so retórno do perelado.

A insulago do ensan doxiso no dia 11 de novembro de 1953, data em que o encho foi nistumio as $6 \mathrm{~kg}$ do torra, em tambor rotativo, e os vasos lom theiss. Xa recheram calchio apenas os vasos relativos aos tratamentos testemunha goral o testemunha sem calcírio; os demais 
receberam terra com calcário na base de uma e duas doses, segundo os tratamentos. Instalado o ensaio, no mesmo dia cada vaso foi umedecido com 11/2 litros de água, a fím de ativar a ação do calcário no solo, e em seguida coberto com o próprio coletor invertido, para evitar evaporação excessiva.

No dia 20 de novembro foram feitas aplicaçôes dos adubos em solução, nas bases citadas, e procedeu-se à semeação, utilizando-se 10 sementes por vaso. As sementes de soja germinaram em 25 de novembro e em $1 .^{\circ}$ ide dezembro foi feito um desbaste, deixando-se quatro plantas por vaso. No dia 26 de janeiro de 1954 foram feitas observações sôbre o desenvolvimento das plantas, comprovadas com fotografias, e nessa mesma data efetuou-se a colheita da parte aérea, cortando-se as plantas rente ao solo. $O$ material colhido foi sêco em estufa a $60-70^{\circ} \mathrm{C}$ e pesado, determinando-se os teores de cálcio e magnésio nas fôlhas.

\section{3 - RESULTADOS OBTIDOS}

\section{1 - EFEITOS SÔBIRE A ACIDEZ DO SOLO}

Findo o ensaio, o solo foi removido dos vasos e depois de sêco ao ar foi destorroado, homogenizado e passado em peneira de $2 \mathrm{~mm}$. Para cada repetição foram determinados o $\mathrm{pH}$ e o $\mathrm{H}^{+}$trocável. Determinou-se o pH na suspensão obtida com $10 \mathrm{~g}$ de terra e $25 \mathrm{ml}$ de água destilada, após 3 horas de repouso. $\mathrm{O} \mathrm{H}^{+}$trocável ou adsorvido foi determinado por agitação de $5 \mathrm{~g}$ de terra com $100 \mathrm{ml}$ de solução normal de acetato de cálcio (2). Os resultados obtidos são apresentados no quadro 1.

Quadro 1.-Resultados da análise do solo, dois meses e meios após a instalação do ensaio. Os valores do hidrogênio trocável são expressos em equivalentes miligramas por 100 gramas de solo

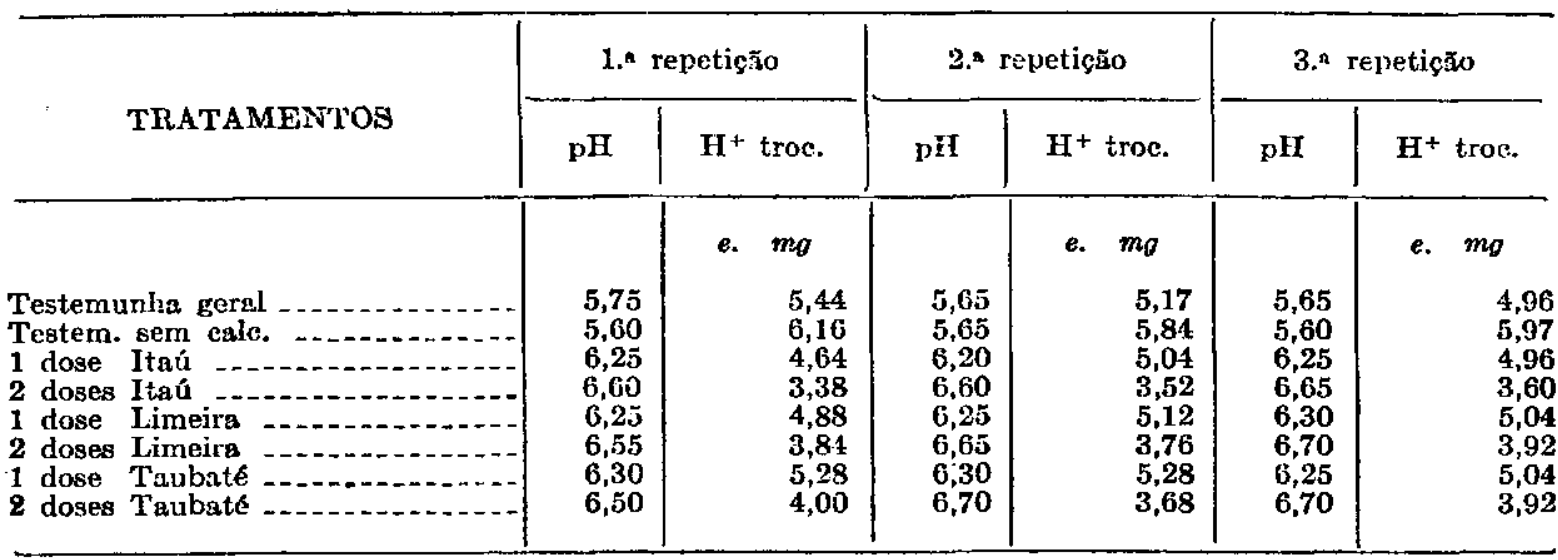

Os dados do quadro 1 mostram a influência de três tipos diferentes de materiais calcários sôbre o $\mathrm{pH}$ e o teor de $\mathrm{H}^{+}$trocável do solo.

Segundo os resultados apresentados, todos os materiais calcários aumentaram de forma significativa o $\mathrm{pH}$ do solo e diminuiram os teores de $\mathrm{H}^{+}$trocável, em relação aos valores dos tratamentos sem calcário. 
Analisando-se os dados do quadro 1, pode-se observar que os solos de todos os tratamentos que receberam calcário, independentemente da natureza do material usado, tiveram seu $\mathrm{pH}$ elevado com o aumento da quantidade de calcário adicionada. Os teores de $\mathrm{H}^{+}$trocável decresceram no mesmo sentido, isto é, diminuiram à medida que a quantidade de calcário aumentou.

Comparando-se os resultados de $\mathrm{pH}$ e $\mathrm{H}^{+}$trocável para uma e duas doses dos calcários calcítico e dolomíticos, conclui-se que, para doses idênticas, não se registraram variações apreciáveis entre êsses dados.

Não houve diferença entre o $\mathrm{pH}$ do tratamento testemunha sem calcário, quando comparado ao tratamento testemunha geral. $\mathrm{O} \mathrm{H}^{+}$trocável do tratamento sem calcário, no entanto, foi ligeiramente mais elevado em tôdas as repetições.

Por conseguinte, com apôio nos resultados obtidos, pode-se dizer que os efeitos determinados pelos materiais calcários calcítico e dolomíticos na acidez do solo foram pràticamente idênticos. As pequenas variações apresentadas são de pouca importância agronômica. Provàvelmente, maiores diferenças poderão ser obtidas aumentando-se o tempo de ação do calcário no solo.

Segundo foi verificado em trabalhos anteriores $(\mathbf{3 , 4})$, os calcários estudados podem ser diferençados pela solubilidade em solução de ácido acético a $1 \%$, solução esta que permite refletir em conjunto as características do material, como composição química, propriedades físico-químicas, características mineralógicas etc. Em outras palavras, a solubilidade em solução de ácido acético a $1 \%$ possibilita identificar o material, isto é, se se trata de um calcário altamente cálcico ou de um calcário dolomítico e, entre êstes, se o material é do tipo sedimentar ou de natureza cristalina.

Os dados desta experiência preliminar vêm demonstrar que, apesar dos calcários utilizados neste trabalho apresentarem solubilidade distinta em ácido acético a $1 \%$, por serem diferentes, os efeitos determinados no solo sôbre o $\mathrm{pH}$ e o $\mathrm{H}^{+}$trocável foram iguais ou semelhantes, nos três casos.

Ainda que a solubilidade em solução diluída de ácido acético constitúa um valioso auxiliar na caracterização, identificação e classificação dos calcários, como o é o ácido cítrico a $2 \%$ para os fosfatos naturais, não se pode, diante dos dados obtidos, estimar a provável atividade do material no solo ou comparar o valor agronômico dos calcários, apoiandose nos resultados obtidos em laboratório, em condições determinadas e comparáveis, o que, aliás, já foi ventilado em trabalho anterior (3).

As quantidades de calcários calculadas teóricamente como suficientes para conduzir o solo à saturação em bases de $70 \%$, não elevaram o pH ao valor esperado 6,5 mas o $\mathrm{pH}$ médio de nove repetições foi de 6,25 , o que pode ser tido como resultado satisfatório, dada a duração de apenas $21 / 2$ meses da experiência. Deve-se considerar, todavia, que a reação dos calcários com o hidrogênio do solo é relativamente lenta, razão pela qual 
revestem-se de importância o grau de finura e o tempo de contato das partículas de calcário com o solo.

O fato de os calcários calcítico e dolomiticos não apresentarem diferença sugere que, na aquisição de um material calcário para fins de corretivo, satisfeitas as condiçóes de grau de finura, o prim€iro requisito a ser considerado é o custo por unidade de equivalente quilograma de neutralizante $\left(^{2}\right)$.

\section{2 - EFEITOS SOBRE A PRODUÇÃO DE MATERIAL SECO}

No quadro 2 são apresentados os pesos de material sêco correspondentes à parte aérea (hastes e fôlhas) e os resultados da análise de cálcio e magnésio de fôlhas de soja, na ocasião da colheita do ensaio.

Quadro 2.-Produções de material sêco dos diferentes tratamentos de ensaio de soja em vasos. Porcentagem de cálcio e magnésio nas fôlhas, no final do ensaio

\begin{tabular}{|c|c|c|c|}
\hline \multirow{2}{*}{ TRATAMENTOS } & $\begin{array}{l}\text { Peso de material } \\
\text { séco }\end{array}$ & \multicolumn{2}{|c|}{$\begin{array}{l}\text { Quantidade do elemento } \\
\text { no material sêco }\end{array}$} \\
\hline & Hastes e folhas & \multicolumn{2}{|c|}{ Fôlhas } \\
\hline & $g$ & $\underset{\%}{\mathrm{CaO}}$ & $\underset{\%}{\mathrm{MgO}}$ \\
\hline $\begin{array}{l}\text { Testemunha geral } \\
\text { Testem. sem ealc. } \\
\text { 1 dose Itá } \\
2 \text { doses Itaú } \\
1 \text { dose Limeira } \\
2 \text { doses Iimeira } \\
1 \text { dose 'Taubaté } \\
2 \text { doses Taubaté }\end{array}$ & $\begin{array}{r}26 \\
133 \\
175 \\
181 \\
198 \\
207 \\
210 \\
217\end{array}$ & $\begin{array}{l}1,48 \\
1,47 \\
1,80 \\
2,10 \\
1,76 \\
1,99 \\
1,76 \\
2,08\end{array}$ & $\begin{array}{l}0,73 \\
0,80 \\
0,86 \\
0,89 \\
1,08 \\
1,28 \\
1,16 \\
1,32\end{array}$ \\
\hline
\end{tabular}

A figura 1 reune duas fotografias tomadas também no dia em que se procedeu à colheita do ensaio (dois meses após a germinação). Pela fotografia $A$ percebe-se, de forma nítida, o maior desenvolvimento das plantas de soja contidas no vaso 3 (1 dose de calcário de Limeira) sôbre as plantas dos vasos 2 (testemunha sem calcário) e $\mathbf{1}$ (testemunha geral). A inspeção da fotografia $B$ não permite diferençar visualmente o desenvolvimento das plantas contidas nos vasos 1 ( 1 dose de calcário Itaú), 4 (1 dose de calcário de Limeira) e 7 (1 dose de calcário de Taubaté), o que, no entanto, foi possível através do pêso de material sêco, que possibilitou uma comparação de ordem quantitativa.

Não obstante a soja mostre-se tolerante até certo ponto à acidez do solo, as produções de hastes e fôlhas foram mais elevadas em todos os tratamentos com calcário.

(2) 0 numero de e. $\mathrm{kg}$ de neutralizante existente em $100 \mathrm{~kg}$ de calé́rio é dado pela soms : \% CaO/28 + $\% \mathrm{MgO} / 20$. 

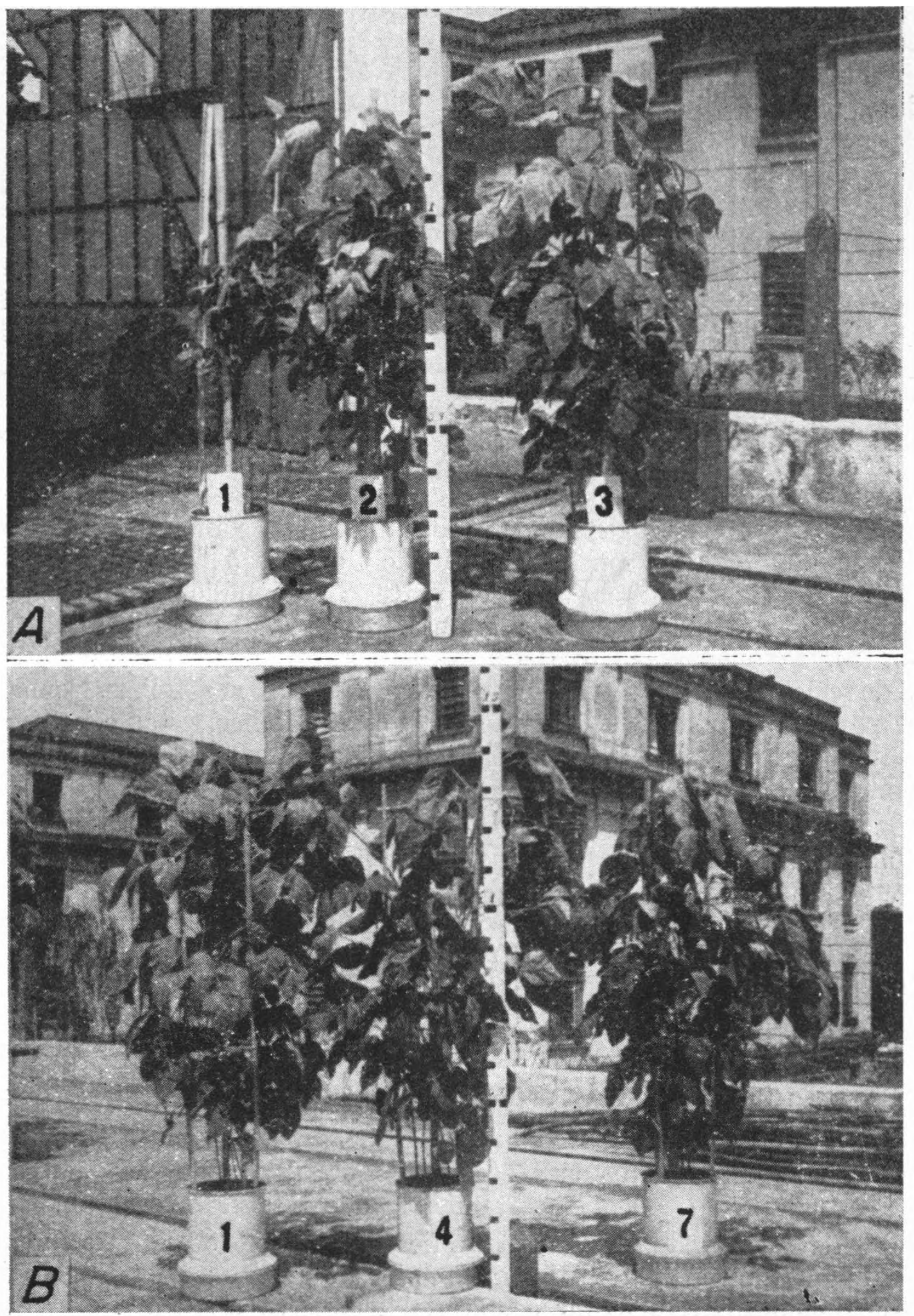

Figura 1. - $A$ - Comparação entre os tratamentos com e sem calcário: 1testemunha geral; 2- NPK, sem calcário; 3- NPK + 1 dóse de calcário de Limeira; $B$ - Comparação entre os tratamentos que receberam 1 dóse de calcário: 1- calcário de Itaú; 4- calcário de Limeira; 7- calcário de Taubaté. (Fotografias tiradas dois meses após a germinação). 
Tomando-se por referência o tratamento testemunha sem calcário, os acréscimos porcentuais de produção de material sêco sôbre a produção de material sêco dêsse tratamento, atribuidos à ação do calcário, foram os seguintes : 1 dose de calcário Itaú, 32; 2 doses de calcário Itaú, 36; 1 dose de calcário de Limeira, $49 ; 2$ doses de calcário de Limeira, $56 ; 1$ dose de calcário de Taubaté, 58; 2 doses de calcário de Taubaté, 63.

Como se nota, a produção de material sêco de hastes e fôlhas foi maior nos tratamentos que receberam calcário dolomítico. A maior produção de soja para feno, procedente de solos tratados com calcários dolomíticos, em relação aos tratados com calcários calcíticos, tem sido apontada por outros autores (6). A soja é uma planta exigente em magnésio e a produção mais baixa dos tratamentos com calcário calcítico pode ser atribuida ao teor menos elevado em magnésio, nos tecidos da planta. Webb e colaboradores (7) estudaram o efeito do magnésio sôbre a produção da soja e verificaram que, em geral, uma deficiência de magnésio, em qualquer período de crescimento da planta, afeta sensivelmente a produção de sementes e vagens; tem efeito moderado sôbre a produção de hastes, pecíolos e raízes e pequena influência quanto à produção de folíolos. Segundo êsses autores, a maior parte do magnésio acumula-se nas fôlhas, onde a atividade é mais intensa. Conforme citam Hammond e outros (5), da quantidade total de cálcio e magnésio da planta madura, $77 \%$ de cálcio e $66 \%$ de magnésio estão contidos nas fôlhas. Como a maior parte de cálcio e magnésio acumula-se nas fôlhas, estas constituem, por conseguinte, a parte vegetal mais importante para o contrôle dêsses elementos.

Os resultados obtidos (quadro 2) mostram que o teor de magnésio das fôlhas foi maior nos tratamentos com calcário dolomítico e cresceu com a quantidade aplicada. Não houve, entretanto, variação ponderável quanto ao teor em cálcio, para doses idênticas. Os dados relativos à porcentagem de magnésio contida nas fôlhas estão de acôrdo com a ordem de produçāo de material sêco apresentada.

\section{4 - CONCLUSÕES}

As conclusóes mais importantes que os dados obtidos permitem tirar são as seguintes :

a) Houve um aumento significativo do $\mathrm{pH}$ do solo e um decréscimo de $\mathrm{H}^{+}$trocável, em todos os tratamentos que receberam calcário.

b) Não foi notada diferença significativa no $\mathrm{pH}$ e $\mathrm{H}^{+}$trocável do solo para quaisquer dos três tipos de materiais usados : calcário calćtico, calcário dolomítico sedimentar e calcário dolomítico cristalino.

c) $\mathrm{O} \mathrm{pH}$ do solo cresceu e o $\mathrm{H}^{+}$trocável decresceu com o aumento da quantidade de calcário calcítico ou dolomítico.

d) A quantidade de calcário adicionada ao solo, calculada a partir do $\mathrm{pH}$ e do $\mathrm{H}^{+}$trocável, para elevar a porcentagem de saturação em bases a $70 \%$ ou a um $\mathrm{pH}$ correspondente de 6,5 , produziu um resultado razoàvelmente satisfatório, em relação ao esperado. 
e) Todos os tratamentos que receberam calcário, indistintamente do tipo de calcário empregado, permitiram um maior desenvolvimento das plantas de soja, em relação ao tratamento sem calcário.

f) A produção de hastes e fôlhas foi maior nos solos tratados com calcário dolomítico do que nos que receberam calcário altamente cálcico.

g) O teor de magnésio nas fôlhas foi mais elevado nos tratamentos com calcário dolomítico e cresceu com a quantidade aplicada. O teor de cálcio para doses idênticas praticamente não variou com o calcário empregado.

h) Os resultados relativos à porcentagem de magnésio contida nas fôlhas e à produção de material sêco de hastes e fôlhas variaram no mesmo sentido.

\section{EFFECT OF THREE TYPES OF LIMESTONE ON SOIL REACTION AND SOYBEAN GROWTH}

\section{SUMMARY}

A study was made of the effect of three types of finely powdered limestone (calcitic, typical dolomitic, and sedimentary dolomitic) on soil acidity, on the development of soybean plants growing in treated soil, and on the mineral content of their leaves.

The experiment was carried out under greenhouse conditions in Mitscherlich pots filled with the "terra roxa misturada" type of soil. Eight treatments with three replications were compared. Equal amounts of $\mathrm{N}, \mathrm{P}_{2} \mathrm{O}_{5}$, and $\mathrm{K}_{2} \mathrm{O}$ were added to all pots, except to one of the controls. Another control received the fertilizers but no limestone. Two levels of each of the three types of limestone were tested. The limestones were finely powdered, and a mixture of equal parts of the fractions obtained through the Tyler sieves $65-150$ and 150-270 was used.

The following data were taken $21 / 2$ months after the experiment was started: a) soil reaction ( $\mathrm{pH})$ and exchangeable hydrogen; b) calcium and magnesium content of the leaves; c) growth of the plants and weight of dry matter. The results obtained indicated that under the conditions of the experiment the three types of limestone induced the same changes in $\mathrm{pH}$ and the same decrease of exchangeable hydrogen in the soil. Amounts of limestone sufficient to saturate about $70 \%$ of the exchange capacity increased the $\mathrm{pH}$ to a satisfactory level as was expected. The three types of limestone increased the growth of the plant and the amount of dry matter produced. The dolomitic limestone gave the greatest increases. For the same type of limestone the increase in dry matter was greater in plants that received the higher level of the treatment.

\section{LITERATURA CITADA}

1. BEACHER, R. L., LONGENECKER, D. \& MERKLE, F. G. Influence of form, fineness, and amount of limestone on plant development and certain soil characteristics. Soil. Sci. 73:75-82. 1952.

2. CATANi, R. A. \& Gallo, J. R. Avaliação da exigência em calcário dos solos do Estado de São Paulo, mediante correlação entre o $\mathrm{pH}$ e a porcentagem de saturação em bases. Rev. Agric., Piracicaba 30:49-60. 1955.

3. GALLO, J. R. Estudo da solubilidade, em solução de ácido acético a $1 \%$, de alguns materiais calcários de grau de finura comercial. Bragantia 13:[133]-138. 1954. 
4.

\& CATANI, R. A. Solubilidade de alguns tipos de calcários. Braganti̊ 13:[63]-74. 1954.

5. HAMMOND, L. C., BLACK, C. A. \& NORMAN, A. G. Nutrient uptake by soybeans on two Iowa soils. Ames, Iowa agric. Exp. Sta., 1951. p. 463-512. (Res. Bull. N. ${ }^{\circ} 384$ )

6. MEYER, T. A. \& VOLK, G. W. Effect of particle size of limestones on soil reaction, exchangeable cations, and plant growth. Soil Sci. 73:37-52. 1952.

7. WEBB, J. T., OHLROGGE, A. J. \& BARBER, S. A. The effect of magnesium upon the growth and phosphorus content of soybean plants. Soil Sci. Soc. Am. Proc. 18:458-462. 1954. 